\title{
ANALISIS PERHITUNGAN BIAYA PRODUKSI PADA PT. FAJAR UTAMA INTERMEDIA
}

\author{
Emilia Nurdin', Yuli Lestari Labangu², Yaya Septiani Rusman ${ }^{3}$
}

\section{Jurusan Akuntansi Fakultas Ekonomi dan Bisnis Universitas Halu Oleo Kendari Sulawesi Tenggara}

\begin{abstract}
ABSTRAK
Penelitian ini bertujuan untuk mengetahui biaya produksi pada PT. Fajar Utama Intermedia dan untuk menghitung biaya produksi pada PT. Fajar Utama Intermedia dengan metode Variable Costing dan Activity Based Costing. Sumber data yang digunakan dalam penelitian ini berupa sumber data internal perusahaan yaitu data yang diperoleh dari dalam perusahaan yang terdiri atas data primer dan data sekunder. Metode pengumpulan data yang digunakan adalah wawancara dan dokumentasi. Metode yang digunakan untuk menganalisis data dengan cara mendeskripsikan atau menggambarkan data yang telah terkumpul sebagaimana adanya tanpa bermaksud membuat kesimpulan yang berlaku untuk umum atau generalisasi. Hasil penelitian menunjukkan bahwa; (1) biaya produksi pada PT. Fajar Utama Intermedia di dapatkan total jumlah biaya produksi yang dikeluarkan atas kertas, plate, tinta hitam, tinta biru, tinta kuning dan tinta merah selama sebulan adalah Rp. 95,063,430. Sementara biaya tenaga kerja yang dikeluarkan oleh PT. Fajar Utama Intermedia setiap bulannya dengan tenaga kerja sebanyak 17 orang adalah Rp. 40.800.000. Dan selanjutnya adalah biaya overhead pabrik yang terdiri atas biaya overhead tetap dan biaya overhead variabel adalah Rp.398.159.809; (2) Terdapat perbedaan utama antara perhitungan Activity Based Costing dengan perhitungan Variable Costing yaitu terletak pada perlakuan biaya overhead pabrik. Activity Based Costing menggunakan perhitungan biaya overhead pabrik tetap dan variable sedangkan metode variable costing hanya menghitung biaya overhead pabrik variabel saja; (3) Keunggulan dalam perhitungan variable costing adalah sebagai alat perencanaan jangka pendek dalam pengambilan keputusan. Sedangkan pada sistem Activity Based Costing sebagai alat penetapan mark up yang tepat dan sebagai alat penetapan harga jual produk yang tepat
\end{abstract}

Kata Kunci : Biaya Produksi, Variable Costing, Activity Based Costing.

\section{ABSTRACT}

This study aims to determine the production costs at PT. Fajar Utama Intermedia and to calculate production costs at PT. Fajar Utama Intermedia using Variable Costing and Activity based costing methods. Sources of data used in this study are internal company data sources, namely data obtained from within the company consisting of primary data and secondary data. Data collection methods used were interviews and 
documentation.The results showed that; (1) PT. Fajar Utama Intermedia gets the total amount of production costs spent on paper, plate, black ink, blue ink, yellow ink and red ink for a month is Rp. 95,063,430. Meanwhile, the labor costs incurred by PT. Fajar Utama Intermedia every month with a workforce of 17 people is Rp. 40,800,000. And then the factory overhead costs consist of fixed overhead costs and variable overhead costs are Rp. 398,159,809; (2) There is a major difference between the calculation of activity based costing and the calculation of variable costing, which lies in the treatment of factory overhead costs. The calculation of activity based costing uses the calculation of fixed and variable factory overhead costs, while the variable costing method only calculates variable factory overhead costs; (3) The advantage in calculating variable costing is as a short-term planning tool in decision making. Whereas in the activity based costing system as a tool for determining the right mark up and as a tool for determining the right product selling price. Keywords: Production Costs, Variable Costing, Activity Based Costing.

\section{PENDAHULUAN}

Perkembangan industri pada era globalisasi sangat pesat sehingga mengakibatkan meningkatnya persaingan bisnis.Lingkungan bisnis saat ini telah banyak mengalami perubahan seperti teknologi yang maju, daur hidup produk semakin pendek, kerumitan produksi semakin meningkat dan standar kualitas yang dibutuhkan konsumen semakin meningkat sehingga menyebabkan adanya modifikasi yang signifikan dalam praktik manajemen suatu perusahaan.

Penentuan harga pokok produksi merupakan hal yang sangat penting mengingat manfaat informasi harga pokok produksi adalah untuk menentukan harga jual produk,pemantauan realisasi biaya produksi, perhitungan laba rugi periodik serta penentuan harga pokok persediaan produk jadi dan produk dalam proses yang disajikan dalam neraca.

Perhitungan harga pokok produksi, informasi yang dibutuhkan adalah informasi mengenai biaya bahan baku, biaya tenaga kerja, dan biaya overhead pabrik. Ketiga jenis biaya tersebut harus ditentukan secara cermat, baik dalam pencatatan maupun penggolongannya.Dalam menentukan harga pokok produksi dapat menggunakan dua metode yaitu metodeVariable Costing dan metode activity based costing. Pada metodevariabel costing merupakan metode penentuan harga pokok produksi yang mengelompokkan biaya berdasarkan perilaku biaya yang terdiri dari biaya bahan baku, biaya tenaga kerja langsung, dan biaya overhead pabrik variable (L.M Samryn 2008:68). Sedangkan metode activity based costing adalah system informasi biaya yang berorientasi pada penyedia informasi lengkap tenteng aktivitas untuk memungkinkan perusahaan melakukan pengelolaan terhadap aktivitas (Mulyadi 2003:40).Laporan laba rugi yang dihasilkan oleh sistem variabel costing memperlihatkan margin kontribusi barang-barang 
yang dihasilkan, informasi yang sangat berfaedah dalam pengambilan keputusan.Dalam metode variabel costing untuk penentuan harga pokok produksi hanya biaya-biaya produksi variabel saja yang dimasukan dalam persedian dan biaya pokok penjualan.

Pada PT. Fajar Utama Intermedia perusahaan yang bergerak dalam percetakan Koran di daerah Kota Kendari provinsi Sulawesi Tenggara, dengan bahan baku utama kertas dan tinta. Masyarakat di kalangan apapun berusaha mencari pengetahuan atas kejadian terkini agar tidak tertinggal dalam arus kehidupan.Melalui media cetak maupun media elektronik, informasi berita menjadi jauh lebih mudah dan cepat untuk didapatkan.Namun tidak semua kalangan mampu atau merasa nyaman untuk mendapatkan berita secara online.Terdapat beberapa kalangan yang tidak mampu atau tidak nyaman membaca berita melalui layar gadget. Itulah mengapa koran masih diminati sampai sekarang.

Table 1.1 Biaya Bahan Baku PT. Fajar Utama Intermedia

\begin{tabular}{|c|c|r|}
\hline Tahun & \multicolumn{1}{|c|}{$\begin{array}{c}\text { Biaya Bahan } \\
\text { Baku (Rp) }\end{array}$} & \multicolumn{1}{c|}{ Growth (Rp) } \\
\hline 2015 & 4.512 .530 .879 & \multicolumn{1}{c|}{-} \\
\hline 2016 & 4.898 .556 .146 & 386.025 .267 \\
\hline 2017 & 3.663 .096 .451 & $(1.235 .459 .695)$ \\
\hline 2018 & 3.083 .255 .181 & $(579.841 .270)$ \\
\hline 2019 & 2.747 .404 .929 & $(335.850 .252)$ \\
\hline
\end{tabular}

Sumber: Manager keuangan PT. Fajar Utama Intermedia

Pada tabel diatas menunjukan bahwa biaya bahan baku PT. Fajar Utama Intermedia pada tahun 2016 mengalami kenaikan sebesar Rp. 386.025.267, namun ditahun 2017 biaya cetak perusahaan mengalami penurunan sebesarRp. 1.235.459.695, pada tahun 2018 sebesarRp. 579.841.270dan tahun 2019 sebesar Rp. 335.850.252. Biaya cetak yang menurun karena permintaan terus menurun disetiap tahunnya.

\section{Pengertian Biaya}

\section{LANDASAN TEORI}

Menurut Siregar dkk (2014:23), biaya adalah pengorbanan sumber ekonomi untuk memperoleh barang atau jasa yang diharapkan memberikan manfaat sekarang atau masa yang akan datang".Sedangkan pengertian biaya menurut Mulyadi (2015:8) adalah "pengorbanan sumber ekonomis yang diukur dalam satuan uang, yang telah terjadi, sedang terjadi atau yang kemungkinan akan terjadi untuk tujuan tertentu”..

\section{Harga Pokok Produksi}

Menurut Mulyadi (2015:14) harga pokok produksi adalah total biaya-biaya yang terjadi untuk mengelola bahan baku menjadi produk yang siap untuk dijual. Menurut 
Bastian (2008:40) penentuan harga pokok adalah bagaimana memperhitungkan biaya kepada suatu produk atau pesanan atau jasa, yang dapat dilakukan dengan cara memasukkan seluruh biaya produksi atau hanya memasukkanunsur biaya produksi variabel saja. Sedangkan menurut Carter dan Usry (2009:40) pengertian harga pokok produksi adalah biaya manufaktur juga disebut biaya produksi atau biaya pabrik biasanya didefinisikan sebagai jumlah tiga elemen biaya : bahan baku langsung, tenaga kerja langsung, dan overhead pabrik.

\section{Variable Costing}

Menurut Mulyadi (2015:18) Variable Costing merupakan metodepenentuan kos produksi yang hanya memperhitungkan biaya produksi yang berperilaku variabel ke dalam kos produksi, yang terdiri dari biaya bahan baku, biaya tenaga kerja langsung dan biaya overhead pabrik variabel. Penentuan harga pokok variabel (variable costing) adalah suatu konsep penentuan harga pokok yang hanya memasukkan biaya produksi variabel sebagai elemen harga pokok produk. Biaya produksi tetap dianggap sebagai biaya periode atau atau biaya waktu (period cost) yang langsung dibebankan kepada laba-rugi periode terjadinya dan tidak diperlakukan sebagai biaya produksi, Dengan dipisahkan informasi biaya menurut prilaku dalam hubungannya dengan perubahan volume kegiatan, metode variable costing mampu menghasilkan informasi yang bermanfaat bagi manajemen dalam perencanaan laba jangka pendek, pengendalian biaya tetap yang lebih baik, dan pengambilan keputusan jangka pendek. Hal ini dimungkinkan karena dalam jangka pendek, biaya tetap tidak relevan karena tidak terpengaruh oleh pengambilan keputusan yang dilakukan oleh manajemen.Jika biaya tetap terpengaruh dalam pengambilan keputusan jangka pendek, metode variable costing dapat menyajikan dampak keputusan tersebut terhadap biaya tetap dan laba.

\section{Tujuan Penentuan Harga Pokok Variabel (Variable Costing)}

a. Membantu manajemen untuk mengetahui batas kontribusi (contribution margin) yang sangat berguna untuk perencanaan laba melalui analisa hubungan biaya-volume-laba (cost-profit-volume) dan untuk pengambilan keputusan (decision making) yang berhubungan dengan kebijaksanaan manajemen jangka pendek.

b. Memudahkan manajemen dalam mengendalikan kondisi-kondisi operasional yang sedang berjalan serta menetapkan penilaian dan pertanggungjawaban kepada departemen atau divisi tertentu dalam perusahaan.

\section{Activity based costing}

Activity based costing merupakan perhitungan biaya yang menekankan pada aktivitasaktivitas yang menggunakan jenis pemicu biaya lebih banyak sehingga dapat mengukur sumber daya yang digunakan oleh produk secara lebih akurat dan dapat membantu pihak manajemen dalam meningkatkan mutu pengambilan keputusan perusahaan. 


\section{METODE PENELITIAN}

\section{Objek Penelitian}

Objek penelitian ini biaya produksi pada bulan Desember 2019.

\section{Jenis Data}

a. Data Kualitatif adalah data yang tidak dapat diukur dalam skala numerikii atau angka-angka. Data kualitatif yang digunakan dalam penelitian ini adalah sejarah singkat perusahaan dan proses produksi selama tahun 2019. Informasi yang didapatkan dari manajer keuangan PT. Fajar Utama Intermedia.

b. Data Kuantitatif adalah data yang diukur dalam skala numeric. Data kuantitatif yang digunakan dalam penelitian ini dalam penelitian ini adalah semua data yang sifatnya angka-angka yang berkaitan pada biaya produksi PT. Fajar Utama Intermedia yaitu berupa biaya bahan baku, biaya tenaga kerja langsung, dan biaya overhead pabrik.

\section{Sumber Data}

a. Data primer penelitian ini adalah hasil wawancara langsung dengan pemilik dan manajer keuangan PT. Fajar Utama Intermediadalam perusahaan. Data primer ini terdiri dari, sejarah singkat perusahaan, jumlah karyawan, bagian-bagian yang bersangkutan dengan produksi dan proses produksi.

b. Data sekunder dalam penelitian ini adalah data yang sudah ada di PT. Media Kita Sejahtera dalam bentuk dokumen dan informasi lain terutama pada informasi biaya yang terjadi dalam proses produksi yang dapat membantu dalam menentukan berapa besar biaya yang dibutuhkan dalam proses produksi, antara lain berupa biaya bahan baku, biaya tenaga kerja langsung, dan biaya overhead pabrik.

\section{Metode Analisis Data}

1. Melakukan observasi ke perusahaan untuk mencari tahu metode perhitungan apa yang digunakan perusahaan dalam menentukan biaya produksi

2. Mengambil data biaya-biaya dari perusahaan.

3. Perhitungan biaya-biaya berdasarkan metode Variable Costing dan perhitungan biaya berdasarkan metode activity based costing

4. Setelah menerapkan metodeVariable Costingdanactivity based costing selesai dilakukan, maka dari hasil perhitungan yang telah dilakukan dapat ditarik kesimpulan yang dapat dijadikan bahan pertimbangan perusahaan dalam upaya perhitungan harga pokok produksi yang akurat. 


\section{Definisi Operasional Variabel}

a. Biaya Produksi adalah biaya yang berkaitan dengan perhitungan harga pokok produksi. Biaya produksi terdiri atas biaya bahan baku dan bahan penolong, biaya tenaga kerja dan biaya overhead pabrik PT. Fajar Utama Intermedia.

b. Variable Costing adalah penentuan harga pokok produksi yang hanya membebankan biaya-biaya produksi variable saja kedalam harga pokok produk. Harga pokok produk menurut metode Variable Costingterdiri aatas biaya bahan baku, biaya tenaga kerja variable dan biaya overhead pabrik variable.

c. Activity based costing (ABC) system menghitung setiap biaya pada masing-masing aktivitas dengan dasar alokasi yang berbeda untuk masing-masing aktivitas seperti unit level activity, batch level activity, product level activity dan facility level activity.

\section{HASIL DAN PEMBAHASAN}

Data biaya bahan baku yang digunakan untuk proses percetakan Koran pada PT. Fajar Utama Intermedia dapat dilihat pada tabel dibawah ini.

Tabel 2 Pemakaian Bahan Baku Pada Bulan April, 2020

\begin{tabular}{|c|l|c|r|r|}
\hline No & Bahan & Terpakai & Harga Sat (Rp) & Jumlah (Rp) \\
\hline 1 & Kertas & 6250 & Rp. 10,300 & Rp. 64,375,000 \\
\hline 2 & Plate & 468 & Rp. 24,300 & Rp. $11,372,400$ \\
\hline 3 & Tinta Hitam & 88 & Rp. 62,750 & Rp. $5,522,000$ \\
\hline 4 & Tinta Biru & 78 & Rp. 60,500 & Rp. 4,719,000 \\
\hline 5 & Tinta Kuning & 75 & Rp. 60,500 & Rp. 4,537,500 \\
\hline 6 & Tinta Merah & 75 & Rp. 60,500 & Rp. 4,537,500 \\
\hline \multicolumn{3}{r}{ Total } & & Rp. 95,063,430 \\
\hline
\end{tabular}

Sumber: Data Perusahaan Tahun 2020

Tabel diatas dapat dijelaskan bahwa biaya bahan baku yang digunakan selama sebulan adalah Rp. 95,063,430 dengan rincian atas pemakaian kertas, plate, tinta hitam, tinta biru, tinta kuning dan tinta merah. Jumlah tenaga kerja dalam perusahaan PT. Fajar Utama Intermedia Informasi ada 98 orang. Dengan rincian sebagai berikut:

Tabel 3 Tenaga Kerja PT. Fajar Utama Intermedia

\begin{tabular}{|l|l|c|}
\hline \multicolumn{2}{|c|}{ Jenis Tenaga Kerja } & Jumlah \\
\hline $\begin{array}{l}\text { Tenaga Kerja } \\
\text { Langsung }\end{array}$ & Tenaga kerja bagian percetakan & 17 orang \\
\hline
\end{tabular}


Jurnal Akuntansi dan Keuangan (JAK)

Volume 6, No. 2 Oktober Tahun 2021

Page: 215 - 228

http://ojs.uho.ac.id/index.php/jak-uho/issue/archive

e-ISSN: 2088-4656

\begin{tabular}{|l|l|l|}
\hline Tenaga Kerja & Tenaga kerja bagian informasi & 60 orang \\
\cline { 2 - 3 } Tidak Langsung & Tenaga kerja bagian Redaksi & 21 orang \\
\hline
\end{tabular}

Sumber: Data Primer, PT. Fajar Utama Intermedia, 2020

Tabel diatas, dijelaskan bahwa total tenaga kerja pada PT. Fajar Utama Intermedia adalah 98 orang yang terdiri atas tenaga kerja langsung dan tenaga kerja tidak langsung.

1. Tenaga kerja bagian informasi $=60$ orang

2. Tenaga kerja bagian Redaksi $=21$ orang

3. Tenaga kerja bagian percetakan $=17$ orang

Biaya overhead pabrik yang ada pada PT. Fajar Utama Intermedia adalah biaya-biaya bahan pembantu seperti biaya listrik, telepon, bahan bakar minyak, biaya kebersihan, perlengkapan pabrik, pemeliharaan pabrik dan lain-lain.

Tabel 4. Biaya Overhead Pabrik Pada Bulan April, Tahun 2020

\begin{tabular}{|c|c|c|c|c|}
\hline $\begin{array}{c}\text { Biaya } \\
\text { overhead } \\
\text { pabrik }\end{array}$ & Bulan & $\begin{array}{l}\text { Biaya Overhead } \\
\text { Tetap (Rp) }\end{array}$ & $\begin{array}{c}\text { Biaya Overhead } \\
\text { variabel }(\mathbf{R p})\end{array}$ & Total (Rp) \\
\hline $\begin{array}{l}\text { Bahan baku } \\
\text { penolong }\end{array}$ & $\begin{array}{l}\text { Bulan } \\
\text { April }\end{array}$ & - & Rp. $\quad 20.505 .000$ & Rp. $\quad 20.505 .000$ \\
\hline $\begin{array}{l}\text { Upah tenaga } \\
\text { kerja tidak } \\
\text { langsung }\end{array}$ & $\begin{array}{l}\text { Bulan } \\
\text { April }\end{array}$ & Rp. 194.400 .000 & - & Rp. 194.400 .000 \\
\hline Bahan bakar & $\begin{array}{l}\text { Bulan } \\
\text { April }\end{array}$ & - & Rp. $\quad 16.200 .000$ & Rp. 16.200 .000 \\
\hline $\begin{array}{l}\text { Biaya } \\
\text { kebersihan }\end{array}$ & $\begin{array}{l}\text { Bulan } \\
\text { April }\end{array}$ & Rp. $\quad 2.400 .000$ & - & Rp. $\quad 2.400 .000$ \\
\hline $\begin{array}{l}\text { Listrik, Air, dan } \\
\text { Telepon }\end{array}$ & $\begin{array}{l}\text { Bulan } \\
\text { April }\end{array}$ & - & Rp. $\quad 27.800 .182$ & Rp. $\quad 27.800 .182$ \\
\hline Biaya cetak & $\begin{array}{l}\text { Bulan } \\
\text { April }\end{array}$ & - & Rp. $\quad 97.654 .500$ & Rp. 97.654 .500 \\
\hline $\begin{array}{l}\text { Biaya } \\
\text { pemakaian suku } \\
\text { cadang mesin } \\
\text { cetak }\end{array}$ & $\begin{array}{l}\text { Bulan } \\
\text { April }\end{array}$ & - & Rp. $\quad 4.500 .000$ & Rp. $\quad 4.500 .000$ \\
\hline $\begin{array}{l}\text { Biaya } \\
\text { perlengkapan } \\
\text { pabrik }\end{array}$ & $\begin{array}{l}\text { Bulan } \\
\text { April }\end{array}$ & - & Rp. 12.650 .127 & Rp. 12.650 .127 \\
\hline $\begin{array}{l}\text { Perbaikan dan } \\
\text { pemeliharaan } \\
\text { mesin }\end{array}$ & $\begin{array}{l}\text { Bulan } \\
\text { April }\end{array}$ & Rp. $\quad 2.800 .000$ & Rp. $\quad 2.800 .000$ & Rp. $\quad 2.800 .000$ \\
\hline
\end{tabular}


Jurnal Akuntansi dan Keuangan (JAK)

Volume 6, No. 2 Oktober Tahun 2021

Page: 215 - 228

http://ojs.uho.ac.id/index.php/jak-uho/issue/archive

e-ISSN: 2088-4656

\begin{tabular}{|l|l|lc|c|c|}
$\begin{array}{l}\text { Penyusutan } \\
\text { bangunan }\end{array}$ & $\begin{array}{l}\text { Bulan } \\
\text { April }\end{array}$ & Rp. 4. 500.000 & & Rp. 4. 500.000 \\
\hline $\begin{array}{l}\text { Penyusutan } \\
\text { mesin }\end{array}$ & $\begin{array}{l}\text { Bulan } \\
\text { April }\end{array}$ & Rp. 8.450.000 & - & Rp. 8.450 .000 \\
\hline $\begin{array}{l}\text { Penyusutan } \\
\text { kendaraan }\end{array}$ & $\begin{array}{l}\text { Bulan } \\
\text { April }\end{array}$ & Rp. 6.300.000 & - & Rp. 6.300 .000 \\
\hline \multicolumn{2}{|c|}{ Total } & Rp 218.850.000 & Rp 179.309.809 & Rp 398.159.809 \\
\hline
\end{tabular}

Sumber : PT. Fajar Utama Intermedia, 2020

Pada Perusahaan PT. Fajar Utama Intermedia hanya bagian percetakan yang merupakan tenaga kerja langsung, dengan rincian sebagai berikut: Upah minimum provinsi $(\mathrm{UMP})=$ Rp. 2.400.000. Untuk biaya tenaga kerja langsung perbulannya adalah :

17 orang x Rp. $2.400 .000=$ Rp. 40.800 .000$.

Jadi upah tenaga kerja langsung pada PT. Fajar Utama Intermedia adalah Rp. 40.800.000

Berdasarkan hasil perhitungan biaya produksi pada PT. Fajar Utama Intermedia di dapatkan total jumlah biaya produksi yang dikeluarkan atas kertas, plate, tinta hitam, tinta biru, tinta kuning dan tinta merah selama sebulan adalah Rp. 95,063,430. Sementara biaya tenaga kerja yang dikeluarkan oleh PT. Fajar Utama Intermedia setiap bulannya dengan tenaga kerja sebanyak 17 orang adalah Rp. 40.800.000. Dan selanjutnya adalah biaya overhead pabrik yang terdiri atas biaya overhead tetap dan biaya overhead variabel adalah Rp.398.159.809

Biaya produksi tersebut meliputi biaya bahan baku langsung, bahan penolong, tenaga kerja langsung, tenaga kerja tidak langsung, biaya overhead pabrik variable dan biaya overhead pabrik tetap. Pada biaya overhead pabrik tetap yaitu biaya penyusutan peneliti menjumlahkan penyusutan setiap aset pada tiap bulannya dan dibagi menjadi tiga, karena aset tersebut di manfaatkan dalam produksi.

Biaya produksi pada PT. Fajar Utama Intermedia dengan metode Variable Costing dan Activity based costing

Adapun analisa perbandingan perhitungan harga pokok produksi dengan menggunakan metode variabel costing dan Activity based costing dapat dilihat dari table 5

Tabel 5. Perhitungan variable costing Pada Bulan April Tahun 2020

\begin{tabular}{|l|c|}
\hline \multicolumn{1}{|c|}{ Variabel Costing } & Total (Rp) \\
\hline Biaya Bahan Baku & Rp. 95.063 .430 \\
\hline Tenaga Kerja Langsung & Rp. 40.800 .000 \\
\hline Biaya Overhead Pabrik Variabel & Rp. 179.309 .809 \\
\hline Total Harga Pokok Produk & Rp. 315.173.239 \\
\hline
\end{tabular}

Sumber Data : Hasil Olahan Tahun 2020 
Menurut perhitungan metode full costing perolehan harga pokok produksi sebesar Rp 315.173.239. Dalam hal ini terlihat bahwa peranan metode variabel costing sebagai salah satu meetode perhitungan harga pokok produksi berperan penting untuk meningkatkan kefektifitasan sebuah perusahaan dalam menentukan biaya-biaya yang dibutuhkan selama proses produksi produk yang diinginkan oleh konsumen. Dan metode variabel costing ini diharapkan juga dapat membantu perusahaan untuk kedepannya sebagai bahan evaluasi yang dapat digunakan untuk menghitung harga pokok produksi untuk setiap produk yang di buat sehingga menentukan harga jual yang efektig dan menghasilkan keuntungan sesuai yang diharapkan.

\section{Perhitungan Biaya Produksi Menggunakan Metode Activity Based Costing}

1. Tahap Pertama

Tahap pertama menentukan harga pokok produksi berdasarkan sistem Activity Based Costing adalah menelusuri biaya dari sumber daya ke aktivitas yang mengkonsumsinya.

Tabel 6. Unit level activity

\begin{tabular}{|l|l|c|}
\hline Level aktivitas & \multicolumn{1}{|c|}{ Komponen BOP } & Jumlah (Rp) \\
\hline \multirow{2}{*}{$\begin{array}{l}\text { Unit level } \\
\text { activity }\end{array}$} & Biaya bahan penolong & Rp. 20.505.000 \\
\cline { 2 - 3 } & Biaya listrik, air, dan telepon & Rp. 27. 800.182 \\
\cline { 2 - 3 } & Biaya bahan bakar & Rp. 16.200.000 \\
\hline \multicolumn{2}{|l|}{ Jumlah biaya } & Rp. 64.505.182 \\
\hline
\end{tabular}

Sumber: Data Hasil Olahan, 2020

Tabel diatas dapat dijelaskan bahwa jumlah biaya Unit level activity sebesar Rp. 64.505.182 yang terdiri atas Biaya bahan penolong, Biaya listrik, air, dan telepon serta Biaya bahan bakar

Tabel 7. Batch level activity

\begin{tabular}{|l|l|l|}
\hline Level Aktivitas & \multicolumn{1}{|c|}{ Komponen BOP } & Jumlah (Rp) \\
\hline \multirow{3}{*}{ Batch level activity } & $\begin{array}{l}\text { Biaya tenaga kerja tidak } \\
\text { langsung }\end{array}$ & Rp. 194.400.000 \\
\cline { 2 - 3 } & $\begin{array}{l}\text { Biaya pemakaian suku } \\
\text { cadang mesin cetak }\end{array}$ & Rp. 4.500.000 \\
\hline Jumlah Biaya & & Rp. 198.900.000 \\
\hline
\end{tabular}

Sumber: Data Hasil Olahan, 2020

Tabel diatas dapat dijelaskan bahwa jumlah biaya Batch level activity sebesar Rp. 198.900.000 yang terdiri atas biaya tenaga kerja tidak langsung dan biaya pemakaian suku cadang mesin cetak. 
Jurnal Akuntansi dan Keuangan (JAK)

Volume 6, No. 2 Oktober Tahun 2021

Page: 215 - 228

http://ojs.uho.ac.id/index.php/jak-uho/issue/archive

e-ISSN: 2088-4656

Tabel 8. roduct level activity

\begin{tabular}{|c|c|c|}
\hline & Komponen BOP & Jumlah (Rp) \\
\hline \multirow{2}{*}{$\begin{array}{l}\text { Product sustaining } \\
\text { activity }\end{array}$} & Biaya cetak & Rp. $\quad 97.654 .500$ \\
\hline & Biaya perlengkapan pabrik & $\begin{array}{ll}\text { Rp. } & 12.650 .127\end{array}$ \\
\hline Jumlah Biaya & & Rp. 110.304.627 \\
\hline
\end{tabular}

Sumber: Data Hasil Olahan, 2020

Tabel diatas dapat dijelaskan bahwa jumlah biaya Product sustaining activity sebesar Rp. 110.304.627 yang terdiri atas biaya cetak dan biaya perlengkapan pabrik.

Tabel 9. Facility level activity

\begin{tabular}{|l|l|c|}
\hline Level Aktivitas & Komponen BOP & Jumlah (Rp) \\
\hline \multirow{5}{*}{ Facility sustaining activity } & $\begin{array}{l}\text { Biaya perbaikan dan } \\
\text { pemeliharaan mesin }\end{array}$ & Rp. 2.800.000 \\
\cline { 2 - 3 } & Biaya kebersihan & Rp. 2.400.000 \\
\cline { 2 - 3 } & Penyusutan bangunan & Rp. 4.500 .000 \\
\cline { 2 - 3 } & Penyusutan mesin & Rp. 8.450 .000 \\
\cline { 2 - 3 } & Penyusutan kendaraan & Rp. 6.300 .000 \\
\hline Jumlah Biaya & & Rp. 24.450.000 \\
\hline
\end{tabular}

Sumber: Data Hasil Olahan, 2020

Tabel diatas dapat dijelaskan bahwa jumlah biaya Facility sustaining activity sebesar Rp. 24.450.000 yang terdiri atas biaya perbaikan dan pemeliharaan mesin, biaya kebersihan, penyusutan kendaraan, penyusutan mesin dan penyusutan bangunan.

\section{Tahap Kedua}

Berdasarkan pembebanan biaya overhead pabrik yang telah dilakukan, maka perhitungan harga pokok produksi dengan menggunakan sistem Activity Based Costing adalah : 
Jurnal Akuntansi dan Keuangan (JAK)

Volume 6, No. 2 Oktober Tahun 2021

Page: 215 - 228

http://ojs.uho.ac.id/index.php/jak-uho/issue/archive

e-ISSN: 2088-4656

Tabel 10. Perhitungan Harga pokok produksi dengan sistem Activity Based Costing pada PT. Fajar Utama Intermedia

\begin{tabular}{|l|c|c|c|c|c|}
\hline \multicolumn{1}{|c|}{ Keterangan } & Unit (Rp) & Batch $($ Rp) & Product $($ Rp) & Facility (Rp) & \multicolumn{1}{|c|}{ Total (Rp) } \\
\hline $\begin{array}{l}\text { Biaya Bahan } \\
\text { Baku }\end{array}$ & Rp. 95.063.430 & & & & Rp. 95.063.430 \\
\hline $\begin{array}{l}\text { Biaya Tenaga } \\
\text { Kerja } \\
\text { Langsung }\end{array}$ & Rp. 40.800.000 & - & - & - & Rp. 40.800.000 \\
\hline $\begin{array}{l}\text { Biaya } \\
\begin{array}{l}\text { Overhead } \\
\text { Pabrik }\end{array}\end{array}$ & Rp. 64.505.182 & Rp. 198.900.000 & Rp. 110.304.627 & Rp. 24.450.000 & Rp. 398.159.809 \\
\hline \multicolumn{7}{|c|}{ Harga Pokok Produksi } & & Rp. 534.023.239 \\
\hline
\end{tabular}

Sumber: Data Hasil Olahan, 2020

Tabel 11. Perbandingan perhitungan biaya produksi menggunakan metode variable costing dan activity based costing

\begin{tabular}{|l|c|cr|}
\hline \multicolumn{1}{|c|}{ Keterangan } & \multicolumn{2}{|c|}{$\begin{array}{c}\text { Variable Costing } \\
\text { (Rp) }\end{array}$} & \multicolumn{2}{|c|}{$\begin{array}{c}\text { Activity Based Costing } \\
\text { (ABC) (Rp) }\end{array}$} \\
\hline Biaya Bahan Baku & Rp. 95.063 .430 & Rp. & 95.063 .430 \\
\hline Biaya Tenaga Kerja Langsung & Rp. 40.800 .000 & Rp. & 40.800 .000 \\
\hline Biaya Overhead Pabrik & Rp. 179.309 .809 & Rp. 398.159 .809 \\
\hline Harga Pokok Produksi & Rp. $\mathbf{3 1 5 . 1 7 3 . 2 3 9}$ & Rp. $\mathbf{5 3 4 . 0 2 3 . 2 3 9}$ \\
\hline
\end{tabular}

Sumber: Data Hasil Olahan, 2020

Berdasarkan hasil perhitungan diatas dapat diketahui bahwa terdapat perbedaan nilai dari hasil perhitungan harga pokok produksi dengan activity based costing dan metode Variabel Costing. perhitungan harga pokok produksi dengan menggunakan metode activity based costing memiliki nilai lebih tinggi dibandingkan dengan perhitungan harga pokok produksi dengan menggunkan metode variable costing, menurut perhitungan metode activity based costing perolehan harga pokok produksi sebesar Rp 534.023.239, sedangkan dengan metode variable costing perolehan harga pokok produksinya sebesar Rp 315.173.239. terdapat selisih perhitungan harga pokok produksi sebesar Rp 218.850.000. perbedaan ini karena adanya selisih dari perhitungan biaya overhead yang dilakukan dengan metode activity based costing dan variabel costing.

Terlihat bahwa perbedaan antara perhitungan harga pokok produksi dengan menggunakan metode activity based costing terletak pada perlakuan overhead pabrik, 
dimana pada metode activity based costing biaya overhead tetap dimasukan dalam harga pokok produksi bersama dengan biaya bahan baku langsung, biaya tenaga kerja langsung, dan biaya overhead pabrik tetap. Sedangkan pada metode variabel costing biaya overhead tetap tidak dimasukan kedalam harga pokok produksi, oleh karena itu perhitungan metode variabel costing tersebut membuat harga pokok produksi yang dihasilkan oleh metode ini menjadi lebih rendah dari harga pokok produksi yang dihasilkan oleh metode activity based costing.

Sistem Activity Based Costing mampu menghasilkan perhitungan biaya yang lebih akurat dibandingkan dengan sistem variable costing.Perhitungan harga pokok produksi menggunakan Activity Based Costing dapat memperlakukan biaya dengan tepat, sehingga menghasilkan perhitungan harga pokok produk yang tepat pula. Dengan perhitungan harga pokok produksi yang tepat dan penetapan mark up yang tepat, perusahaan dapat menetapkan harga jual produk dengan tepat. Dengan menggunakan pendekatan metode variabel costing, akan membantu perusahaan sebagai alat perencanaan dan pengambilan keputusan-keputusan jangka pendek yang tidak mengharuskan pertimbangan tentang biayabiaya non produksi. Variable costing juga baik digunakan saat ingin melakukan perhitungan perhari atau perminggu karena dalam variabel costing tidak dihitung biaya overhead pabrik tetap. Keunggulan dalam perhitungan variable costing adalah sebagai alat perencanaan jangka pendek dalam pengambilan keputusan. Sedangkan pada sistem activity based costing adalah dapat mengalokasikan biaya aktivitas ke setiap produk secara tepat. Hasil penelitian ini masih mendukung teori yang dinyatakan oleh Mulyadi (2009:13-16) menyimpulkan bahwa bahan baku merupakan bahan yang membentuk bagian menyeluruh produk jadi. Adapun biaya yang dikeluarkan oleh PT. Fajar Utama Intermedia adalah biaya bahan baku, tenaga kerja langsung dan biaya overhead pabrik variabel.

Penelitian yang dilakukan Amelia Lambajang, 2013, perbedaan perhitungan harga pokok produksi antara metode perusahaan dan metode full costing, karena metode perusahaan perhitungannya masih sederhana dan belum terperincidalam pengklasifikasian biayanya. Sedangkan metode full costing sudah memperhitungkan semua biaya yang dibutuhkan pada saat proses produksi secara rinci, dan memperhitungkan biaya overhead variabel dan biaya overhead tetap.

\section{KESIMPULAN, IMPLIKASI, KETERBATASAN, DAN REKOMENDASI Kesimpulan}

1. Perhitungan biaya produksi pada PT. Fajar Utama Intermedia di dapatkan total jumlah biaya produksi yang dikeluarkan atas kertas, plate, tinta hitam, tinta biru, tinta kuning dan tinta merah selama sebulan adalah Rp. 95,063,430. Sementara biaya tenaga kerja yang dikeluarkan oleh PT. Fajar Utama Intermedia setiap bulannya 
dengan tenaga kerja sebanyak 17 orang adalah Rp. 40.800.000. Dan selanjutnya adalah biaya overhead pabrik yang terdiri atas biaya overhead tetap dan biaya overhead variabel adalah Rp.398.159.809

2. Berdasarkan perhitungan biaya produksi dengan menggunakan metode activity based costing dan metode variable costing yang telah dibuat penulis, metode activity based costing didapat hasil senilai Rp. 534.023.239, sedangkan perhitungan biaya produksi menggunakan variable costing didapat hasil lebih kecil yaitu senilai Rp. 315.173.239

\section{Implikasi}

Berdasarkan hasil penelitian tersebut dapat dikemukakan implikasi secara teoritis dan praktis

\section{Keterbatasan}

Dalam suatu penelitian tentunya hasil penelitian yang disajikan tidak terlepas dari keterbatasan- keterbatasan yang menyebabkan hasil suatu penelitian tidak sempurna. Begitupula dengan penelitian pada skripsi ini yang meneliti tentang Analisis Perhitungan Biaya Produksi Pada PT. Fajar Utama Intermedia. Keterbatasan itu adalah informasi yang diperoleh oleh penulis yang diberikan oleh perusahaan tersebut sangat minim sekali, sehingga penulis kesulitan dalam mendapatkan informasi yang lebih untuk melakukan penelitian tersebut.

\section{Rekomendasi}

1. Sebaiknya perusahaan menggunakan perhitungan harga pokok produksi dengan mengadopsi metode pesanan yang memasukkan semua unsur biaya overhead pabrik yang dikeluarkan.

2. Sebaikanya perusahaan menerapkan klasifikasi biaya yang lebih tepat sesuai dengan kelompoknya sehingga mudah didalam melakukan perhitungan harga pokok produksi.

3. Sebaiknya perusahaan membuat sistem alokasi biaya yang lebih tepat

\section{DAFTAR PUSTAKA}

Arfan, ikhsan.2013. Teori Akuntansi. Bandung : Medanetera dan Ciptapustaka.

Carter dan Usry. 2009 .Akuntansi Biaya, Buku Satu, Edisi Tiga Belas, Jakarta: Selemba Empat,2006

Firdaus dan Wasilah Abdullah. 2009. Akuntansi Biaya. Jakarta: Salemba Empat.

Mulyadi. 2015. Ekonomi Sumber Daya Manusia dalam Perspektif Pembangunan. PT. Rajagrafindo Persada. Jakarta. 
Jurnal Akuntansi dan Keuangan (JAK)

Volume 6, No. 2 Oktober Tahun 2021

Page: 215 - 228

http://ojs.uho.ac.id/index.php/jak-uho/issue/archive

e-ISSN: 2088-4656

Samryn, L. M. 2015. Pengantar akuntansi : metode akuntansi untuk elemen laporan keuangan diperkaya dengan perspektif IFRS dan perbankan. Jakarta : PT RajaGrafindo Persada

Siregar.dkk. 2014.Akuntansi Biaya. Edisi 2. Jakarta: Salemba Empat

Supriyono.2011. Akuntansi Biaya Pengumpulan Biaya dan Penentuan Harga Pokok, Buku 1 Edisi 2. Yogyakarta: BPFE.

Warren,Carl S., James M. Reeve dan Philip E. Fess. (2009). Pengantar Akuntansi. Buku Satu Edisi Kedua Puluh Satu. Penerbit Salemba Empat: Jakarta 